\title{
Os artifícios da cosmologia
}

\author{
MELO NETO, João Evangelista \\ Tude de. Nietzsche à luz dos \\ antigos: a cosmologia. São Paulo: \\ Editoria Unifesp, 2020, 168 p.
}

Filipe Campello*

"Quando todos os corpos celestes retornarem ao mesmo ponto, o que sempre acontece a cada 36 mil anos, os mesmos efeitos, tal como eles se apresentam agora, também repetir-se-ão". Essa poderia ser apenas mais uma entre tantas previsões e elucubrações, não fosse o fato de constar entre as 219 teses condenadas em 1277 por decisão do bispo de Paris, Étienne Tempier, e uma comissão de dezesseis professores de teologia. A questão é: por que essa tese cosmológica seria tão perigosa para o cristianismo?

Nietzsche não apenas acreditava ter a resposta, como também soube se valer dela para jogar com as mesmas cartas. É o que mostra João Neto em Nietzsche à Luz dos antigos: a Cosmologia. Resultado de parte do material de sua tese de doutorado, João defende neste trabalho que para compreendermos a cosmologia nietzschiana precisamos voltar aos filósofos pré-socráticos. Mas o modo como

\footnotetext{
*Professor de Filosofia da Universidade Federal de Pernambuco, Recife, PE, Brasil.

ORCID https://orcid.org/0000-0003-1954-0421

Correio eletrônico: filipe.campello@ufpe.br
}

Cad. Nietzsche, Guarulhos/Porto Seguro, v.42, n.2, p. 233-238, maio/agosto, 2021.| 233 
Campello, F.

João se propõe a reconstruir esse retorno não é nem através da exegese dos fragmentos desses filósofos, tampouco uma reconstrução da interpretação nietzschiana dos antigos. Ao invés disso, o trabalho apresenta um caminho que vai de Nietzsche para os antigos e de volta: Trata-se de partir dos problemas enfrentados por Nietzsche em sua cosmologia, de pensar com Nietzsche, e, com ele, reencontrar suas fontes.

Mas a experiência que tive ao ler o trabalho de João e do que pude aprender com ele não se reduz a de um mero leitor. Isso porque o que encontrei de novidade ao longo de minha leitura se confunde, no meu caso, às lembranças de uma amizade atravessada pela filosofia. Eu e João começamos juntos o curso de graduação em filosofia da Universidade Federal de Pernambuco. Contemporâneos de turma que fomos, já naqueles primeiros anos lembro bem o jeito entusiasmado de João em falar da cosmologia nietzschiana. Não sei se ele ainda lembra de uma noite durante um evento em João Pessoa, quando ficamos por horas conversando sobre o eterno retorno e sua provocativa máxima moral - aja como sua ação se repetisse eternamente -, já antevendo ali o quanto esse tema poderia vir a se tornar seus interesses de pesquisa futuros.

Em meio a essas andanças, a leitura de seu livro trouxe-me a grata alegria em ver os desdobramentos de questões que já tinham se tornado familiar sobretudo pela verdadeira paixão filosófica que João demonstrava ao falar delas. E trazer essas lembranças pouco usuais em uma resenha significa não apenas um detalhe biográfico, senão que o modo que João lê Nietzsche e, com ele, os antigos, pode ser visto enquanto filosofia da vida, não apenas no sentido do diálogo com a biologia e a ciência do seu tempo - como é com frequência associado a Nietzsche-, mas também a partir da vida enquanto biografia. Parafraseando Kant, encontramos no mundo aquilo que nele colocamos. 
Com isso em mente, voltemos à questão da censura daquela tese ameaçadora. A forma com que Nietzsche a retoma, talvez tão apaixonadamente quanto João, é perspicaz: e se a cosmologia for apenas um artifício para justificar uma determinada visão moral de mundo? Essa pode ser uma questão cuja resposta pode ter ligado Nietzsche ao cristianismo, mas por motivos contrários. Pois ambos estão se valendo de teses cosmológicas como fundamento de visões morais do mundo, extraindo dali resultados antagônicos. Se precisamos de uma cosmologia como fundamento - diria Nietzsche - que a usemos. $\mathrm{O}$ projeto poderia ser lido de modo irônico, como uma espécie de cosmologia negativa: um Nietzsche que enfrenta os fundamentos da visão moral do mundo com a cartas capazes de efetivamente derrubá-la.

Em As paixões e os interesses, trabalho seminal na história das ideias econômicas, Albercht Hirschman apresenta uma tese sobre o conceito de interesse que, apesar de situar em âmbitos distintos, traz semelhanças com essa interpretação. Pois, para Hirschman, o discurso moderno de consolidação do interesse no contexto do surgimento do capitalismo, que ligava este conceito à racionalidade e oposto às paixões, seria somente uma artimanha retórica. Ao invés de racional, o interesse seria, ele mesmo, uma paixão, mais precisamente o que Hirschman chama de uma paixão equivalente contrária.

Talvez faça sentido dizer que o projeto da cosmologia nietzschiano é o de uma paixão equivalente contrária. Trata-se, como lemos no livro de João, de um esforço teórico de solapar as bases cosmológicas da visão moral do mundo não apenas declarando-a falsa, mas substituindo-a por outra: uma força equivalente contrária. Se uma tese cosmológica representa uma ameaça aos valores da tradição cristã, é porque tal visão moral só se sustenta por uma cosmologia, e que, portanto, só pode se sentir de fato ameaçada ao se deparar com a possibilidade de seu colapso. Como lemos na introdução, 
Campello, F.

a 6 a tese condenada representava uma ameaça ao cristianismo porque ela teria o poder de abalar os fundamentos da cosmovisão cristã e, assim, produzir uma reviravolta valorativa na cristandade. Na verdade, esse raciocínio denota que diferentes cosmovisões podem, por vezes, desempenhar a função de legitimar e conservar uma determinada tábua de valores de uma sociedade, mas, em certas ocasiões, podem assumir o papel de promover uma drástica modificação no sistema de valores estabelecido. No nosso entender, é justamente essa relação orgânica entre cosmovisão e valores que Nietzsche tem em mente quando se dedica a elaborar uma cosmologia (Melo Neto, 2020, p. 16).

Um dos recursos empregados por Nietzsche, como se sabe, foi encontrar no debate científico de seu tempo indícios que pudessem conferir uma roupagem cientificista à sua teoria. Mas mesmo nessa busca de fundamentação, vemos a engenhosidade retórica que pudesse trazer como efeito o abalo da cosmovisão cristã. Daí ele passar a empreender as energias em um ambicioso projeto de transvaloração dos valores, que nortearia a última fase de seu pensamento. É sobre essa fase que se debruça o trabalho, propondo-se a realizar uma interpretação dos principais temas que caracterizam os textos de Nietzsche nesse período. Mas ao invés de se voltar às interlocuções com a ciência de sua época - aspecto já mais consolidado na Nietzscheforschung - o trabalho se dedica a entender como essas bases são derivadas de outros importantes aliados de Nietzsche: os antigos. Nessa empreitada, as estratégias metodológicas são distintas: enquanto no primeiro capítulo se parte “do 'Heráclito de Nietzsche' para chegarmos ao 'Nietzsche heraclitiano"” (p. 15), o segundo capítulo, dedicado à interpretação dos estoicos, retorna aos escritos desses filósofos para a partir deles analisar as reverberações no pensamento nietzschiano. "É em Heráclito e nos estoicos", defende João, "que devemos buscar as raízes de toda cosmologia nietzschiana - e não apenas da doutrina do eterno retorno" (Melo Neto, 2020, p. 13). 
Particularmente instigante é o terceiro capítulo, onde vemos os desdobramentos da originalidade e capacidade interpretativa do trabalho em explorar as nuances da cosmologia Nietzschiana. É ali onde mais reverberam aquelas conversas nos idos de dois jovens estudantes de graduação entusiasmados com a reflexão filosófica. É o que me fez imaginar, nesse emaranhado entre leitura e lembrança, que a cosmologia de Nietzsche seria, ela mesma, criação. Uma criação, contudo, que pretendia ter a força de mudar nossa visão moral do mundo. Um sentido inventivo próprio da filosofia e que, como tal, não permanece no plano da ficção ou do imaginário, mas que atua; que faz da potência, ato. Uma cosmologia inventada para se tornar real. É assim que Nietzsche se mostra como pensador da imanência, o que faria Heidegger ver nele o último grande metafísico, mas um metafísico da imanência que volta aos antigos para trazer o novo. "Minha meta", escreveu Nietzsche já no fim de sua vida, "é provocar uma completa inimizade entre nossa atual 'cultura' e a antiguidade. Quem quiser servir à primeira terá de odiar a esta última" (Nachlass/ FP 3 [68] de março de 1875, KSA 8.33).

Atravessando uma riqueza de citações, notas e referências, o trabalho de João convida o leitor a refazer, com Nietzsche, esse percurso, a recontar essa história. Como uma outra história que eu e João ouvíamos juntos em nossas primeiras aulas de filosofia: quando Tales, ao olhar para o céu, se perguntava por que um universo tão

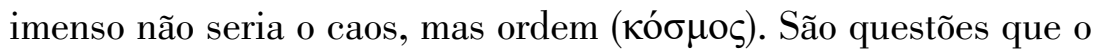
cristianismo e Nietzsche quiserem responder, e quem sabe também João, com a mesma paixão que seu interlocutor, poderá trazer, em trabalhos futuros, sua própria resposta. 
Campello, F.

\section{Referências}

HIRSCHMAN, Albert O. As paixões e os interesses: argumentos políticos para o capitalismo antes de seu triunfo. Rio de Janeiro: Paz e Terra, 1979.

MELO NETO, João Evangelista Tude de. Nietzsche à luz dos antigos: a cosmologia . São Paulo: Editoria Unifesp, 2020.

NIETZSCHE, Friedrich. Sämtliche Werke. Kritische Studienausgabe (KSA), 15 vols. (Organizada por Giorgio Colli e Mazzino Montinari), Berlim: Walter de Gruyter \& Co., 1988.

Enviada: 15/04/2021

Aceita: 21/05/2021

238 | Cad. Nietzsche, Guarulhos/Porto Seguro, v.42, n.2, p. 233-238, maio/agosto, 2021. 